\title{
Targeted Next-Generation Sequencing and Informatics as an Effective Tool to Establish the Composition of Bovine Piroplasm Populations in Endemic Regions
}

\author{
Abdul Ghafar (D), Anson V. Koehler (D), Ross S. Hall, Charles G. Gauci $\mathbb{D}$, Robin B. Gasser and Abdul Jabbar *(D) \\ Department of Veterinary Biosciences, Melbourne Veterinary School, Faculty of Veterinary and Agricultural \\ Sciences, The University of Melbourne, Werribee, VIC 3030, Australia; abdul.ghafar@unimelb.edu.au (A.G.); \\ anson.koehler@unimelb.edu.au (A.V.K.); rossh@unimelb.edu.au (R.S.H.); charlesg@unimelb.edu.au (C.G.G.); \\ robinbg@unimelb.edu.au (R.B.G.) \\ * Correspondence: jabbara@unimelb.edu.au
}

Citation: Ghafar, A.; Koehler, A.V.; Hall, R.S.; Gauci, C.G.; Gasser, R.B.; Jabbar, A. Targeted Next-Generation Sequencing and Informatics as an Effective Tool to Establish the Composition of Bovine Piroplasm Populations in Endemic Regions. Microorganisms 2021, 9, 21. https://dx.doi.org/10.3390/ microorganisms 9010021

Received: 18 November 2020 Accepted: 19 December 2020 Published: 23 December 2020

Publisher's Note: MDPI stays neutral with regard to jurisdictional claims in published maps and institutional affiliations.

Copyright: () 2020 by the authors. Licensee MDPI, Basel, Switzerland. This article is an open access article distributed under the terms and conditions of the Creative Commons Attribution (CC BY) license (https: / / creativecommons.org/ licenses/by/4.0/).

\begin{abstract}
Protists of the genera Babesia and Theileria (piroplasms) cause some of the most prevalent and debilitating diseases for bovines worldwide. In this study, we established and used a next-generation sequencing-informatic approach to explore the composition of Babesia and Theileria populations in cattle and water buffalo in a country (Pakistan) endemic for these pathogens. We collected individual blood samples from cattle $(n=212)$ and water buffalo $(n=154)$, extracted genomic DNAs, PCR-amplified the V4 hypervariable region of $18 \mathrm{~S}$ small subunit rRNA gene from piroplasms, sequenced amplicons using Illumina technology, and then analysed data using bioinformatic platforms. The results revealed piroplasms in $68.9 \%$ (252/366) samples, with overall occurrence being markedly higher in cattle (85.8\%) than in water buffaloes (45.5\%). Babesia (B.) occultans and Theileria (T.) lestoquardi-like species were recorded for the first time in Pakistan, and, overall, T. annulata was most commonly detected $(65.8 \%)$ followed by B. bovis $(7.1 \%)$, B. bigemina $(4.4 \%)$, and T. orientalis $(0.5 \%)$, with the genetic variability within $B$. bovis being pronounced. The occurrence and composition of piroplasm species varied markedly across different agro-ecological zones. The high detection of T. annulata in asymptomatic animals suggested a relatively high level of endemic stability of tropical theileriosis in the bovine population.
\end{abstract}

Keywords: targeted next-generation sequencing; informatics; protist populations; Babesia; Theileria; bovines; $18 \mathrm{~S}$ ribosomal RNA

\section{Introduction}

Tick-borne diseases of ruminants [e.g., cattle (Bos indicus and Bos taurus) and buffalo (Bubalus bubalis)]_including piroplasmosis (i.e., babesiosis and theileriosis)—significantly affect the productivity of livestock globally [1,2], leading to a major adverse impact on food supply and the economy, particularly in Africa, the Americas, Asia, and Australia [3]. Bovine babesiosis is the most important tick-borne disease of cattle, and is caused by Babesia (B.) bovis and B. bigemina (in tropical and sub-tropical regions) as well as $B$. divergens (in the temperate areas) [4-6]. Babesia bovis and B. bigemina are mainly transmitted by Rhipicephalus (Boophilus) microplus and R. (B.) annulatus, and B. divergens by Ixodes ricinus [5,6]. Although vertical transmission is uncommon for Babesia spp., it has been described for $B$. divergens [7]. The clinical manifestation of babesiosis includes anorexia, lethargy, anaemia, icterus, tachycardia, and/or death due to respiratory distress [8,9]. Theileria parva causes bovine theileriosis (known as East Coast Fever, transmitted by R. appendiculatus) in Eastern, Central, and Southern Africa, and T. annulata causes tropical theileriosis (transmitted by Hyalomma spp.) in Southern Europe, Asia, and Africa [10]. The clinical manifestation of tropical theileriosis includes anaemia, hypoxia, enlarged superficial lymph nodes, fever, respiratory distress, and/or death [11]. If animals recover from acute babesiosis and theileriosis, they assume a carrier status (with premunition), in which they maintain long-term 
subclinical infection with piroplasms, which can be ingested by female ticks as they take their blood meal from the animal [12].

Subclinical piroplasm infections are usually not reliably diagnosed by conventional microscopic examination of Giemsa-stained thin and thick blood smears [13] or serological tests, such as the enzyme-linked immunosorbent assay (ELISA) and the indirect fluorescent antibody test (IFAT) [13,14], due to limited sensitivity or specificity. Although conventional (singleplex) PCRs targeting the 18S nuclear ribosomal RNA gene [15] offers suitable analytical sensitivity and specificity [16], most are not able to accurately discern multiple species in a single sample [17]. Although multiplex PCR assays can overcome this limitation, they can be challenging to establish and standardise. On the other hand, next-generation (deep) sequencing (NGS) of amplicons produced by PCR from informative target genes using relatively 'conserved' primers allows the identification of multiple taxa or species within a sample with high specificity and sensitivity, as well as the assessment of genetic variation and their relative abundance [18-21]. The hypervariable V4 region of the nuclear $18 \mathrm{~S}$ rRNA gene is reported to be a suitable target for the identification/classification of piroplasm and the study of population structures [20,22-27].

Given that ticks and tick-borne diseases are a major constraint to the livestock industry and agriculture in Pakistan [28], there have been some epidemiological investigations of piroplasms of bovines using conventional microscopic methods [29-37]. However, there has been no detailed genetic investigation of piroplasm populations in bovines or their ticks in this country. In the present study, we established and employed PCR-based NGS of the V4 region of 18S rRNA to elucidate the composition of piroplasm populations in cattle and buffaloes in distinct geographical regions of Pakistan known to be endemic for these protists.

\section{Materials and Methods}

\subsection{Collection of Blood Samples and DNA Extraction}

The collection of bovine blood samples was approved by the Animal Ethics Committee at the Faculty of Veterinary and Agricultural Sciences, The University of Melbourne (permit no. 714216). From September to November 2017, blood samples $(n=366)$ were collected from the bovine (i.e., cattle and buffalo) populations, with no history of clinical piroplasmosis, located in 25 villages in the districts Bahawalpur, Jhang, Jhelum, Layyah, and Okara of Punjab and 10 villages in districts Sukkur and Thatta of Sindh province (Figure 1). These villages are located in five agro-ecological zones of Pakistan, which differ in climate, land use, and soil type, and the majority of bovine population of Pakistan occurs in these zones [38,39]. Small-holder farms (with $\leq 10$ bovines) from each village were selected because they harbour $>90 \%$ of the bovine population in the country [39]. Blood samples were collected from different age-groups ( $<1$ year, 1-3 years, and $>3$ years) of cattle $(n=212$; male $=38$; female $=174)$ and buffaloes $(n=154 ;$ male $=39$; female $=115)$ via venipuncture using syringes (BD, Franklin Lakes, NJ, USA) into anticoagulant (EDTA)coated vacutainers (BD, Franklin Lakes, NJ, USA). All samples were stored at $-20{ }^{\circ} \mathrm{C}$ prior to further processing.

From aliquots $(100 \mu \mathrm{L})$ of individual blood samples, genomic DNAs were extracted using the DNeasy Blood \& Tissue Kit (Qiagen, Hilden, Germany), according to the manufacturer's recommendations, and were stored at $-20{ }^{\circ} \mathrm{C}$ until further use. 


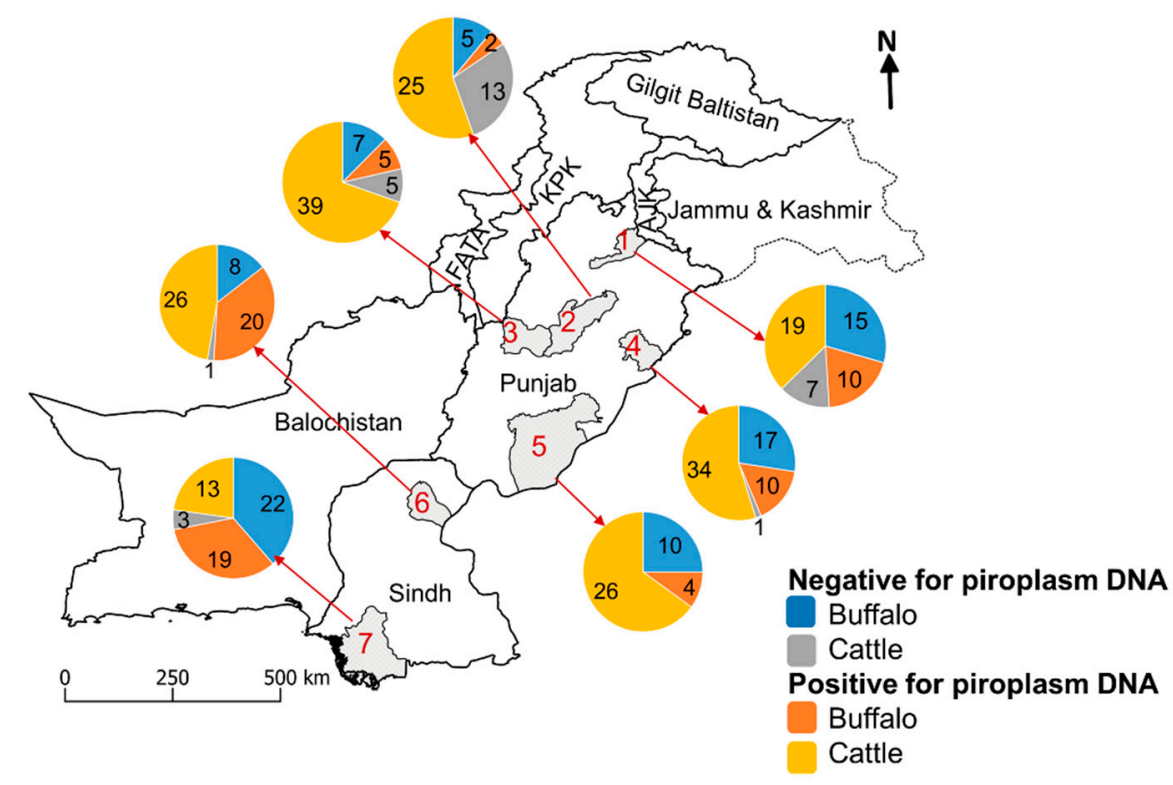

Figure 1. Map of Pakistan showing the numbers of cattle and buffaloes in which piroplasm species were detected in Jhelum (1), Jhang (2), Layyah (3), Okara (4), Bahawalpur (5), Sukkur (6), and Thatta (7) districts of Punjab and Sindh provinces. Abbreviation: FATA, Federally Administered Tribal Area; KPK, Khyber Pakhtunkhwa.

\subsection{PCR-Based Next-Generation Sequencing}

The $18 \mathrm{~S}$ rRNA hyper-variable region V4 was PCR-amplified from individual genomic DNA samples. Primary PCR was achieved using primers RLBF and RLBR [15] bearing $5^{\prime}$-adaptor sequences (F: 5'-GTGACCTATGAACTCAGGAGTC-primer-3'; R: 5'CTGAGACTTGCACATCGC-AGC-primer- $\left.3^{\prime}\right)$. This PCR was carried out in a volume of $25 \mu \mathrm{L}$, containing $3.12 \mathrm{mM}$ of each deoxynucleotide triphosphate (dNTP), $6.25 \mathrm{pmol}$ of each adaptor primer, $125 \mathrm{mM} \mathrm{MgCl}_{2}$, $5 \mathrm{X}$ GoTaq reaction buffer, and $0.6 \mathrm{U}$ of GoTaq flexi DNA polymerase (Promega, Madison, WI, USA). The thermocycling conditions consisted of an initial denaturation at $95^{\circ} \mathrm{C}$ for $5 \mathrm{~min}$ followed by 18 cycles of $95^{\circ} \mathrm{C}$ for $15 \mathrm{~s}, 52{ }^{\circ} \mathrm{C}$ for $20 \mathrm{~s}$, and $72{ }^{\circ} \mathrm{C}$ for $30 \mathrm{~s}$ followed by final elongation at $72{ }^{\circ} \mathrm{C}$ for $7 \mathrm{~min}$. Positive (B. bovis and T. annulata) and negative (template-free and DNA of haemoparasites-free bovine blood) controls were included in each PCR. A subset of samples (10\%) was randomly selected using the "sample()" command in $\mathrm{R}$ version 4.0.3 [40] and used as technical replicates. Amplicons were purified using 1X Ampure Beads (Beckman Coulter, Brea, CA, USA).

Secondary PCR was carried out to introduce 8-base forward and reverse indices (Illumina, San Diego, CA, USA) into individual amplicons (i.e., multiplexing) for subsequent sequencing of all amplicons in a single run. Twenty-three forward and 29 reverse indices were used, allowing multiplexing of 418 amplicons (i.e., 366 samples, 37 replicates, and 15 controls). Triplicates of each of the confirmed positive controls (B. bovis and T. annulata) and negative control samples [DNAs from haemoparasites-free bovine-bloods, and no-DNA i.e., Ambion nuclease-free water (Life Technologies, Austin, TX, USA) used in adaptor PCR as well as in indexing PCR] were used to exclude cross-contamination. Aliquots $(10 \mu \mathrm{L})$ of each purified amplicon from the first PCR was used as a template along with $10 \mu \mathrm{L}$ of OneTaq ${ }^{\circledR} 2$ X Master Mix (New England Biolabs, Ipswich, MA, USA) and $0.5 \mu \mathrm{L}$ of each index. Thermocycling conditions were an initial denaturation at $95^{\circ} \mathrm{C}$ for $3 \mathrm{~min}$ followed by 24 cycles of $95^{\circ} \mathrm{C}$ for $15 \mathrm{~s}, 60{ }^{\circ} \mathrm{C}$ for $30 \mathrm{~s}$, and $72{ }^{\circ} \mathrm{C}$ for $30 \mathrm{~s}$, and a final extension at $72{ }^{\circ} \mathrm{C}$ for $7 \mathrm{~min}$.

Following an assessment of the quality of amplicons using an Agilent 2200 TapeStation (Agilent Technologies, Santa Clara, CA, USA), amplicons were purified using 1X Ampure Beads (Beckman Coulter, Brea, CA, USA). Then, aliquots $(5 \mu \mathrm{L})$ of 418 individual, purified amplicons were pooled and sequenced using a 600 -cycle $(2 \times 300$ bp paired-end reads $)$ 
kit (MiSeq Reagent Kit v3, Illumina San Diego, CA, USA) on a MiSeq platform (Illumina, San Diego, CA, USA).

An evaluation of this nested PCR-based NGS method revealed that the primary and secondary PCRs could reproducibly amplify $\leq 1.0$ picogram $/ \mu \mathrm{L}$ from pure genomic DNA of $B$. bovis or B. bigemina, thereby indicating high analytical sensitivity.

\subsection{Pre-Processing and Analysis of Sequence Data, and Taxonomic Assignment}

The demultiplexing of raw data was carried out using in-house software, resulting in FASTQ sequence files. The paired-end FASTQ files were uploaded into a QIIME2 v. 2019.10 [41] environment for further processing and informatic analyses. Adaptor, primer, and index sequences were trimmed from all forward and reverse reads using cutadapt plugin [42]. Trimmed reads were then imported as QIIME2 compatible ".qza" files. Quality plots were generated for randomly selected 10,000 sequences each from forward and reverse reads separately to assess the read-quality in q2view. This allowed the selection of truncation parameters to remove reads of low quality $(\leq 30)$.

The DADA2 plugin [43] was used to remove chimeras and low-quality reads and to dereplicate and merge paired-end reads. This resulted in ASVs instead of operational taxonomic units (OTU), thus allowing a comparatively accurate measure of diversity [44]. The shorter length reads $(<410 \mathrm{bp})$ and samples with less than a total of 10 reads $(n=11)$ were excluded from further analyses cf. [45]. The SILVA SSU 138 reference database was downloaded (http://www.arb-silva.de/download/arb-files) and all unpublished Babesia spp. and Theileria spp. data removed. The q-2 feature-classifier was used to train and test the curated SILVA database. The curated database was used to classify the ASVs to species/taxa through the scikit-learn classifier [46]. Subsets of ASVs were selected for each species/taxon and their taxonomic assignment verified using BLASTn (NCBI). A taxonomic bar-plot of ASVs was generated using the QIIME2 taxa barplot visualiser. Alpha rarefaction plots were generated using MAFFT [47] and FastTree [48] plugins in QIIME2 to ensure sufficient sequencing depth.

\subsection{Phylogenetic Analyses}

Unique ASVs determined herein were aligned using MUSCLE v.3.8.31 [49] within MEGA 7.0 using default settings [50]. Pairwise comparisons of aligned ASVs were performed to calculate nucleotide differences using BioEdit version X [51]. Subsequently, published, matching reference sequences of Babesia and Theileria spp. from bovines were retrieved from GenBank and aligned with respective piroplasm sequences identified in this study. Alignments were performed using MUSCLE in MEGA using default settings and were then trimmed to uniform lengths of 434 (Babesia spp.) or 459 (Theileria spp.) nucleotides (Figures S1 and S2).

The evolutionary models for individual DNA sequence alignments were determined using the Akaike information criterion test in jModelTest v.3.7 [52]. NJ and ML trees were constructed based on the Tamura-Nei method [53] with gamma-distributed (shape parameter for Babesia spp. $=0.46$ and Theileria spp. $=0.693$ ) site variation and complete deletion using MEGA. The bootstrapping method (10,000 replicates) was used to infer the reliability of internal branches [54]. Babesia microti (GenBank accession no. AY918951) and T. ornithorhynchi (KT937390) were used as outgroups. The phylogenetic trees built using the ML and NJ methods were created using the software FigTree 1.4.3 (http:/ / tree.bio.ed. ac.uk/software/figtree/), and their topologies were compared.

\subsection{Statistical Analyses}

Data were analysed using GraphPad Prism 5 program (GraphPad Software Inc., La Jolla, CA, USA) and R version 3.4.3 [40]. Figure images were produced using Microsoft Excel for Office 365 and ggplot2 [55], phyloseq [56], and/or UpSetR [57] packages in R. 


\subsection{Data Availability Statement}

The NGS data of 18S rRNA produced in the present study are available from the GenBank under accession numbers: MW165561-MW165706 (Theileria annulata), MW165707MW165710 (T. orientalis), MW165716 (T. lestoquardi-like), MW165717-MW165730 (Babesia bovis), MW165731-MW165739 (B. bigemina), and MW165740 (B. occultans).

\section{Results}

\subsection{Sequence Data Sets and Definition of ASVs}

Sequence data were obtained for 252 of the 366 samples analysed. In total, 3,876,271 curated sequence reads represented these 252 samples (182 from cattle and 70 from buffalo), and 175 amplicon sequence variants (ASVs) (mean length: $453 \mathrm{bp}$; standard deviation $=13.4$ ) were recorded (Figures S1 and S2). More ASVs were recorded for Theileria spp. $($ T. annulata $=146, T$. orientalis $=4$, and T. lestoquardi-like $=1)$ than for Babesia spp. $($ B. bovis $=14$, B. bigemina $=9$, and B. occultans $=1)$ (Figures S3 and S4).

Within individual species, pairwise comparison of ASVs (Tables S1 and S2) showed the highest level of variation for B. bovis $(0.3-6.3 \%)$, followed by T. orientalis $(0.3-1.8 \%)$, B. bigemina (0.3-1.4\%) and T. annulata (0.3-0.9\%). For Babesia spp., sequence differences were highest $(21.6-23 \%)$ between $B$. bovis and B. bigemina, followed by $20.2-21.1 \%$ between B. bovis and B. occultans and $7.7-8.1 \%$ between B. bigemina and B. occultans. For Theileria, differences of $7.7-8.1 \%$ were recorded between $T$. lestoquardi-like and T. orientalis, $5.3-7 \%$ between T. annulata and T. orientalis, and $2.2-2.9 \%$ between T. annulata and T. lestoquardi-like.

\subsection{Phylogenetic Relationships of ASVs}

Phylogenetic analyses of 24 ASVs representing the genus Babesia identified three distinct species (Figure 2). As the trees obtained by Maximum Likelihood (ML) and Neighbour Joining (NJ) analyses of ASV data had a very similar topology, only ML trees are presented. Clade 1 contained 14 sequences (BBo1-BBo14 represented as blue circles in Figure 2), which grouped with $18 \mathrm{~S}$ sequences of B. bovis from Australia (GenBank JQ437260), Brazil (GenBank FJ426364), China (GenBank AY603398), and the USA (GenBank L31922), with strong statistical support (bootstrap values of $\mathrm{NJ}=100 \%$ and $\mathrm{ML}=99 \%$ ). The second clade comprised of one ASV (BOC1 represented as red triangle in Figure 2) which clustered with a reference sequence of B. occultans from Pakistan (GenBank MN726547), with moderate to strong nodal support $(\mathrm{NJ}=93 \%$ and $\mathrm{ML}=99 \%)$. Clade 3 consisted nine sequences (BBi1-Bbi9 represented as green squares in Figure 2) which grouped with $18 \mathrm{~S}$ sequences of B. bigemina previously published from Turkey (GenBank KP745623), the USA (GenBank HQ264113), and Uganda (GenBank KU206291), with medium to strong nodal support $(\mathrm{NJ}=85 \%$ and $\mathrm{ML}=98 \%)$.

Phylogenetic analyses of 151 ASVs representing the genus Theileria revealed three clades (Figure 3). The majority of the ASVs in clade 1 (TA1-TA146 represented as blue circles in Figure 3) grouped with reference sequences of T. annulata from Pakistan (GenBank JQ743632 and MN726546) and India (GenBank KY367879), with low statistical support $(\mathrm{NJ}=41 \%$ and $\mathrm{ML}=40 \%$ ). Clade 2 contained one ASV (TLE1 represented as red triangle in Figure 3) that clustered with an $18 \mathrm{~S}$ sequence of T. lestoquardi from China (GenBank AF081135), with weak nodal support $(\mathrm{NJ}=39 \%$ and $\mathrm{ML}=41 \%)$. The third clade comprised four sequences (TOR1-TOR4 represented as green squares in Figure 3) which grouped with reference sequences of T. orientalis complex from Australia (GenBank MG571580), China (GenBank AF236097 and AF081137) and Pakistan (GenBank MG599096), with strong nodal support $(\mathrm{NJ}=96 \%$ and $\mathrm{ML}=97 \%)$. 


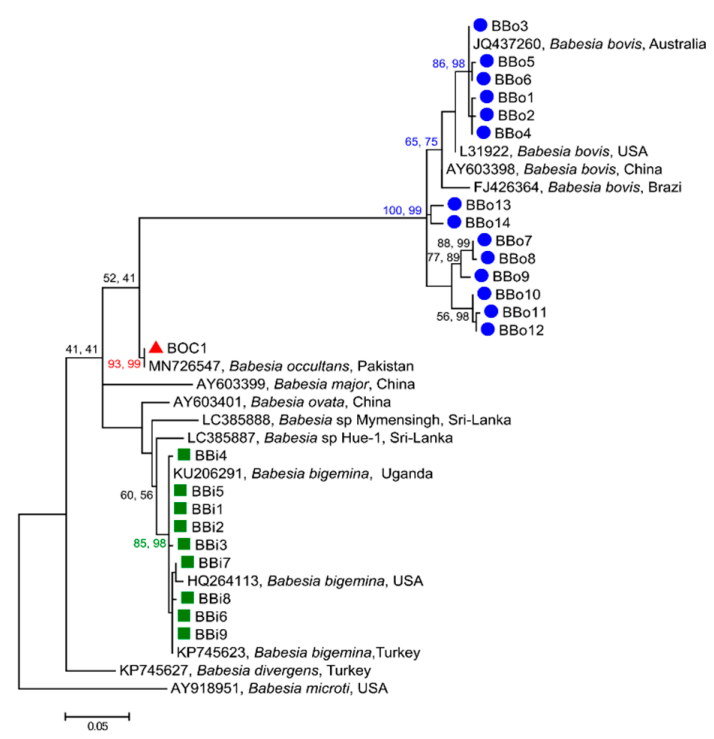

Figure 2. Phylogenetic relationships of amplicon sequence variants (ASVs) of Babesia species determined in this study (coloured symbols) with reference sequences from previous studies. The relationships were inferred based on separate analyses of 18S rRNA sequence data (aligned over 386 bp) using the Maximum Likelihood (ML) and Neighbor-Joining (NJ) methods. Babesia microti (AY918951) was used as outgroup. Nodal support values are indicated as bootstrap values for the NJ (first) and ML (second) method. The scale bar indicates distance.

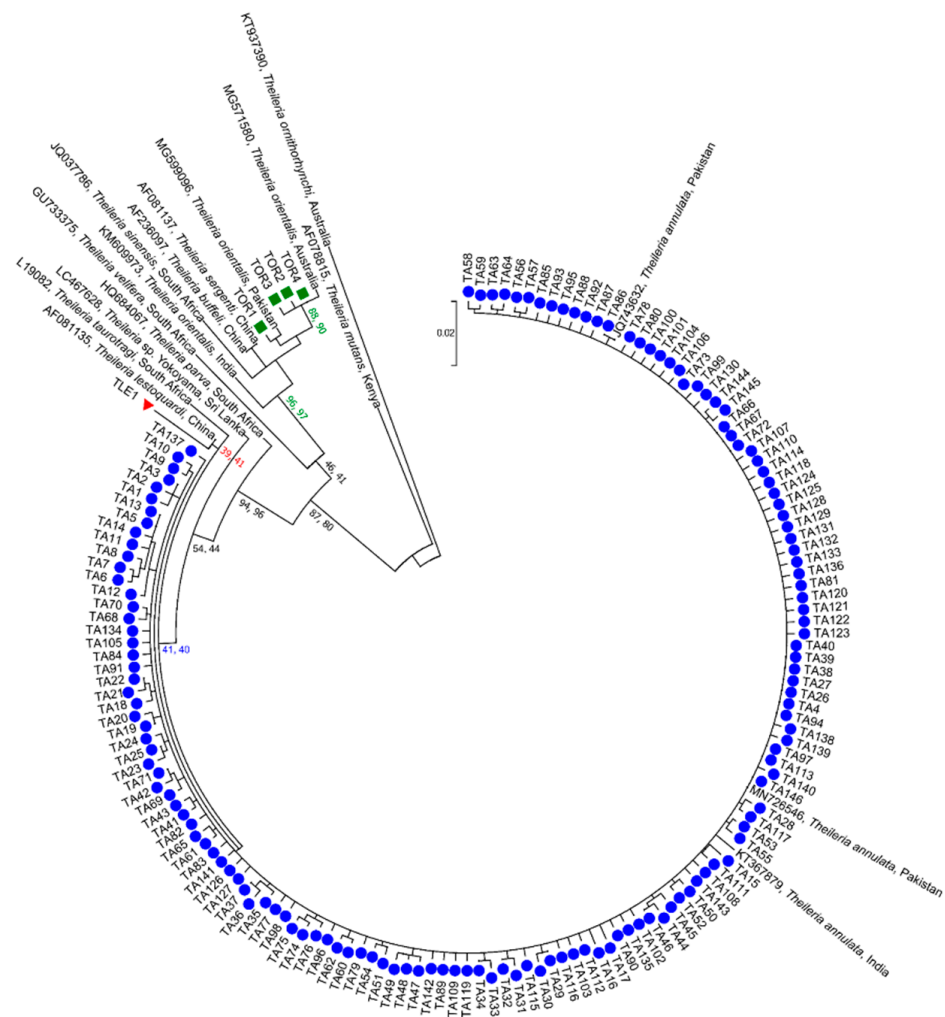

Figure 3. Phylogenetic relationships of amplicon sequence variants (ASVs) of Theileria species determined in this study (coloured symbols) with reference sequences from previous studies. The relationships were inferred based on separate analyses of $18 \mathrm{~S}$ rRNA sequence data (aligned over $386 \mathrm{bp}$ ) using the Maximum Likelihood (ML) and Neighbor-Joining (NJ) methods. Theileria ornithorhynchi (KT937390) was used as an outgroup. Nodal support values are indicated as bootstrap values for the NJ (first) and ML (second) method. The scale bar indicates distance. 


\subsection{Composition of Piroplasm Populations in Individual Bovines}

In total, six piroplasm species belonging to two genera-Babesia and Theileria-were detected using PCR-based NGS. One to six species of piroplasm were detected in 252 $(68.9 \%)$ of all 366 samples (animals) tested (Table 1). Theileria annulata was detected in most $(65.8 \%)$ of the 366 animals from all districts, followed by B. bovis $(7.1 \%)$ and B. bigemina $(4.4 \%)$ from six and four districts, respectively. Theileria orientalis $(0.5 \%)$ was detected only in cattle from two districts (Jhang and Okara), T. lestoquardi-like (0.3\%) was detected in a buffalo from the Thatta district of Sindh and B. occultans $(0.3 \%, 1 / 366)$ in a cow from Layyah (Table 1). Multiple species of piroplasm were detected in 8.5\% (31/366) of bovines studied, with two species in $27(10.7 \%)$ and three in four $(1.6 \%)$ of infected animals (Figure 4). Specifically, B. bovis and T. annulata were detected in 16 bovines, B. bigemina and T. annulata were detected in six, and T. annulata and T. orientalis were detected in two bovines. B. bigemina, B. bovis, and T. annulata were detected in four animals (Figure 4). Coinfections with B. bigemina and B. bovis, T. annulata and T. lestoquardi-like, or T. annulata and B. occultans were detected in individual animals (Figure 4). Overall, more cattle ( $\mathrm{n}=18)$ harboured multiple species of piroplasm than buffaloes $(n=13)$.

Table 1. Piroplasm species detected in bovines from seven districts of Punjab and Sindh, Pakistan.

\begin{tabular}{|c|c|c|c|c|c|}
\hline \multirow{2}{*}{ Piroplasm Species } & \multirow{2}{*}{ District(s) } & \multicolumn{2}{|c|}{ Water Buffalo } & \multicolumn{2}{|c|}{ Cattle } \\
\hline & & Male & Female & Male & Female \\
\hline \multirow{7}{*}{ Theileria annulata } & Okara & - & $10 / 23$ & $7 / 7$ & $27 / 28$ \\
\hline & Jhelum & $3 / 7$ & $7 / 18$ & - & $19 / 22$ \\
\hline & Bahawalpur & - & $4 / 11$ & $5 / 5$ & $21 / 21$ \\
\hline & Layyah & - & $5 / 9$ & $3 / 5$ & $36 / 39$ \\
\hline & Jhang & - & $2 / 7$ & $4 / 4$ & $21 / 34$ \\
\hline & Sukkur & $5 / 9$ & $9 / 19$ & $8 / 8$ & $18 / 19$ \\
\hline & Thatta & $4 / 13$ & $10 / 28$ & $4 / 5$ & $9 / 11$ \\
\hline T. lestoquardi-like & Thatta & $1 / 13$ & - & - & 一 \\
\hline \multirow{2}{*}{ T. orientalis } & Okara & - & - & - & $1 / 28$ \\
\hline & Jhang & - & - & - & $1 / 34$ \\
\hline \multirow{7}{*}{ Babesia bovis } & Okara & - & - & $1 / 5$ & $1 / 28$ \\
\hline & Jhelum & - & - & - & $4 / 22$ \\
\hline & Bahawalpur & - & - & - & $1 / 21$ \\
\hline & Layyah & - & $1 / 9$ & - & $1 / 39$ \\
\hline & Jhang & - & - & - & $1 / 19$ \\
\hline & Sukkur & $1 / 9$ & $4 / 19$ & $1 / 5$ & $2 / 11$ \\
\hline & Thatta & $3 / 13$ & $5 / 28$ & - & - \\
\hline \multirow{5}{*}{ B. bigemina } & Okara & - & - & - & $2 / 28$ \\
\hline & Bahawalpur & - & - & $2 / 5$ & - \\
\hline & Layyah & - & - & - & - \\
\hline & Sukkur & $1 / 9$ & $6 / 19$ & $1 / 8$ & - \\
\hline & Thatta & $1 / 13$ & $1 / 28$ & - & $2 / 11$ \\
\hline B. occultans & Layyah & - & - & - & $1 / 39$ \\
\hline
\end{tabular}




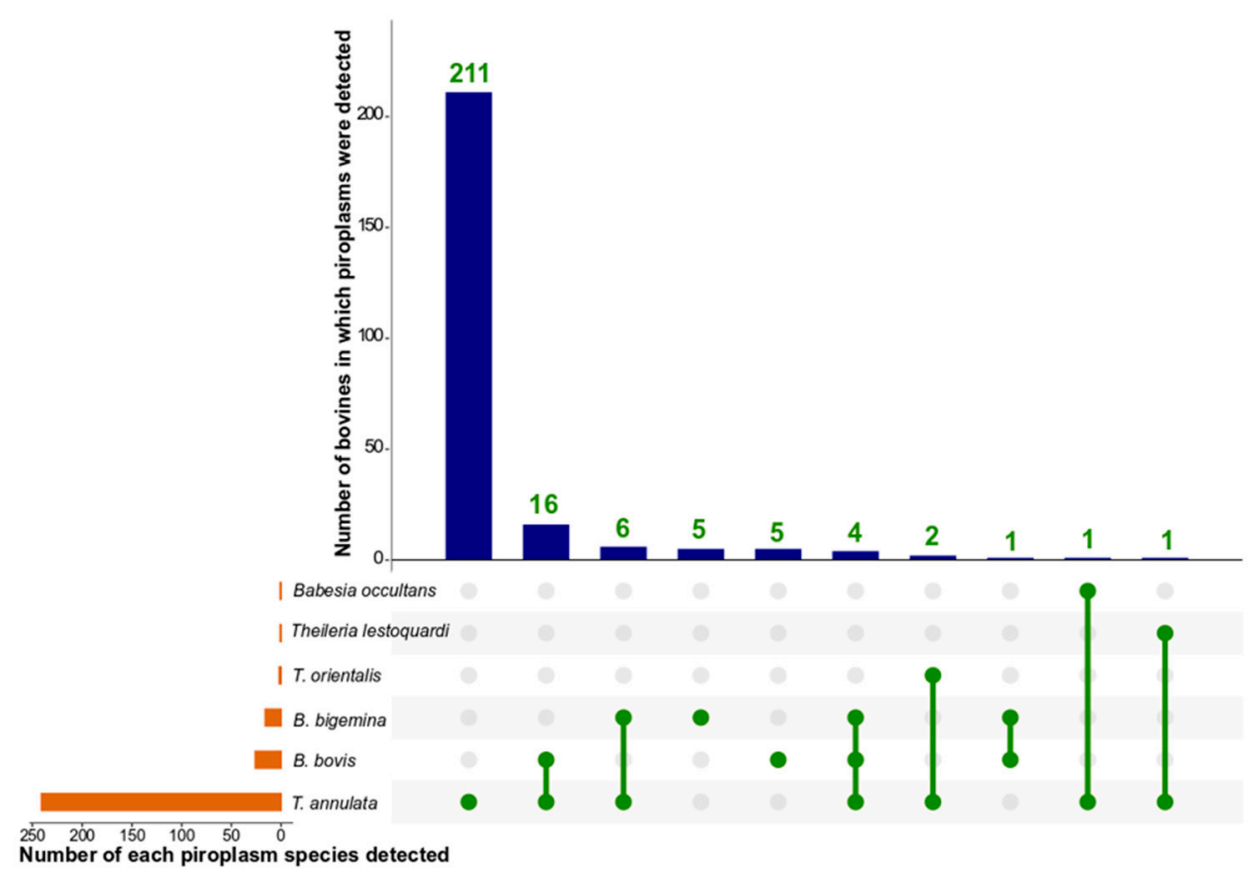

Figure 4. An UpSetR plot of Babesia and Theileria species detected in the tested bovine population in Pakistan by using PCR-based next-generation (deep) sequencing (NGS). The orange horizontal coordinate columns represent the number of samples which were test-positive for each piroplasm species. The blue vertical columns show the numbers of bovines that are positive for single or coinfections of piroplasm species. The green lines connecting green dots indicate coinfecting piroplasm species.

\section{Discussions}

The livestock sector in Pakistan is the mainstay of the agriculture-based economy and contributes $60.6 \%$ of its agricultural share of the gross domestic product [58]. Within this context, $\sim 50$ million cattle (Bos indicus and Bos taurus) and 41 million water buffaloes (Bubalus bubalis) produce $\sim 97 \%$ of the gross milk production in this country [58]. Given that ticks and tick-borne diseases have a major adverse impact on the livestock industry and the dearth of detailed knowledge and understanding of the epidemiology of such diseases in this country [28], there was significant merit in gaining an insight into the abundance and genetic composition of piroplasm populations in the general bovine populations in key farming areas of Pakistan.

The present study showed that piroplasm species are abundant, as they were detected in $68.9 \%$ of 366 individuals representing the general bovine population from five zones. Theileria annulata was the most commonly detected $(95.6 \%, 241 / 252)$, and B. occultans and T. lestoquardi-like were detected for the first time in bovines in this country. The genetic diversity detected within some piroplasm was conspicuous, and exemplified the utility of PCR-directed NGS to identify existing and novel piroplasm taxa of veterinary and/or public health significance. The variation in composition of piroplasm populations in bovines between or among some districts is likely associated with differing prevalences of suitable tick vectors, as indicated recently $[59,60]$, and encourages detailed investigations of the abundance and diversity of pathogens in vector populations.

Theileria annulata - the most abundant piroplasm identified-is the major cause of tropical theileriosis in the region [28]. Tropical theileriosis is one of the most serious constraints on livestock establishments [1,61]. Despite the high abundance of the vector tick, H. anatolicum, in Pakistan $[59,60]$, the abundance of T. annulata was surprising because blood samples were collected from asymptomatic animals during the season when the temperature and prevalence of ticks are usually low [62] and because the indigenous cattle (Bo. indicus) and buffaloes (Bu. bubalis) studied are both naturally resistant to 
TBPs [63-65]. Although previous studies have reported a high prevalence of T. annulata in clinically healthy animals in Pakistan (30-59.8\%) [34,36], Spain (22.4\%) [66], and Turkey (39.3\%) [67], the occurrence estimated herein exceeds most of the previous estimates, which may, at least in part, relate to the high analytical sensitivity of PCR-directed NGS [68,69].

Theileria orientalis-the cause of a "benign" theileriosis-was detected in two cattle from Okara and Jhang districts; this taxon has caused significant outbreaks in countries including Australia, New Zealand, Japan, and the USA [70]. Pathogenic genotypes of T. orientalis have been reported in mammalian and tick hosts in countries of the Asia Pacific, including India [71], Sri Lanka [72], China [73], and Pakistan [34,74]. Some evidence indicates that this species was introduced through the import of infected animals from Australia [74], and we think that future work might focus on assessing the molecular epidemiology of oriental theileriosis in cattle (Bo. taurus) imported to Pakistan from Australia and the USA, as the transmission of this parasite among naïve indigenous breeds of bovines, particularly those owned by small-scale farmers, could lead to outbreaks similar to those which impacted the cattle industry in Australasia over the last decade [75,76].

Babesia was detected more in buffaloes $(14.9 \%, 23 / 154)$ than in cattle $(9.4 \%, 20 / 212)$, which might be explained by greater innate susceptibility of the former to piroplasms $[63,77]$. Interestingly, Babesia in buffaloes was found to a much greater extent (96\%) in Sindh than in Punjab (4\%), which might relate to genetic differences between Nili Ravi and Kundi breeds of buffalo in Punjab and Sindh provinces, respectively, and/or climatic distinctiveness between these two regions, with tick transmission being favoured in Sindh. The 'host genetics' proposal is supported somewhat by results from a Colombian study [78] showing a higher susceptibility of Murrah buffalo than Carabao and crossbred buffaloes to Babesia species. Another study [65] also indicated that the host genotype influences the impact of TBPs in bovines. Further work is required to explore and verify the differences in susceptibility to Babesia spp. between host species and breeds in endemic and non-endemic regions.

The relatively high level of genetic variation (up to $6.3 \%$ in $18 S$ ) within B. bovis accords with previous findings (also 18S) for species of Babesia [79], raising a pertinent question as to whether the distinct ASVs identified here within B. bovis represent population variants or cryptic species. This question warrants investigation using genomic sequencing and informatic tools, as inferences regarding species status based on variation in $18 \mathrm{~S}$ alone may not be entirely unreliable [79-82].

This study records T. lestoquardi-like and B. occultans for the first time in bovines in Pakistan. Although found in buffalo, T. lestoquardi usually causes a malignant form of theileriosis in small ruminants in Pakistan and other parts of the world [83]. Since bovines are often reared together with sheep and goats and this pathogen shares the same tick vector as T. annulata (i.e., H. anatolicum), it is plausible that $T$. lestoquardi has jumped a small ruminant (via the tick) to a new host species (buffalo), similar to cases reported from Iran [84] and Sudan [85]. This is further substantiated by T. lestoquardi being the only piroplasm species of small ruminants which has possibly evolved from a cattle-infecting piroplasm species [86]. This hypothesis is supported by several features shared between both piroplasm species, including the high level of sequence homogeneity, antigenic crossreactivity, overlapping distribution, and the same vector i.e., Hyalomma species $[87,88]$. Interestingly, T. lestoquardi does not appear to cause disease in bovines, but this warrants investigation. Also B. occultans - the other, new record in cattle for the Indian subcontinenthas been recognised as non-pathogenic [89], but was linked to a babesiosis outbreak in cattle in Italy [90]. This species has been recorded previously in $\mathrm{H}$. anatolicum species, from cattle from the same district of Pakistan [91] as this new record in cattle, suggesting active, local transmission from tick to bovine, although this requires verification.

In conclusion, this study demonstrates the utility and benefits of using PCR-coupled NGS to directly explore piroplasm populations in host animals with mixed infections and to discover species or operational taxonomic units, undetectable using conventional techniques. Given its analytical sensitivity and specificity, this NGS approach should provide a powerful tool to explore temporal and spatial changes in piroplasm compositions 
in both livestock animals and associated tick vectors, and could also be used to assist in assessing the effectiveness of anti-piroplasm vaccines or the impact of host genotype (bovine species or breed) on susceptibility/resistance to piroplasm infections. More broadly, this tool could be adapted and applied to investigating piroplasm species of other host species and zoonotic representatives infecting humans.

Supplementary Materials: The following are available online at https://www.mdpi.com/2076-2 607/9/1/21/s1, Figure S1: Nucleotide alignment of the 18S rRNA amplicon sequence variants of Babesia species (B. bovis, BBo1-Bbo14; B. occultans, BOC1; B. bigemina, BBi1-BBi9). A dot indicates an identical nucleotide with respect to the top sequence. Figure S2: Nucleotide alignment of amplicon sequence variants (18S rRNA) of Theileria species (T. orientalis, TOR1-TOR4; T. lestoquardi-like, TLE1; T. annulata, TA1-TA146). A dot indicates an identical nucleotide with respect to the top sequence. Figure S3. Relative abundance of $18 \mathrm{~S}$ sequences of Babesia species in individual bovine blood samples from distinct districts in Pakistan. Figure S4. Relative abundance of $18 \mathrm{~S}$ sequences of Theileria species in individual bovine blood samples from distinct districts in Pakistan. Table S1: Pairwise comparison of $18 \mathrm{~S}$ rRNA nucleotide amplicon sequence variant sequences belonging to Theileria (T. orientalis, TOR1-TOR4; T. lestoquardi-like, TLE1; T. annulata, TA1-TA146) species determined herein. Nucleotide similarity and percentage differences are given above and below the diagonal, respectively. Table S2: Pairwise comparison of $18 \mathrm{~S}$ rRNA nucleotide amplicon sequence variant sequences belonging to Babesia species (B. bovis, BBo1-Bbo14; B. occultans, BOC1; B. bigemina, BBi1$\mathrm{BBi} 9)$ determined herein. Nucleotide similarity and percentage differences are given above and below the diagonal, respectively.

Author Contributions: Conceptualization, A.J., R.B.G., and A.G.; methodology, A.J. and R.B.G.; software, A.G., A.V.K., and R.S.H.; validation, A.G., A.J., R.B.G., A.V.K., and R.S.H.; formal analysis, A.G., A.V.K. and R.S.H.; investigation, A.G., A.J., and R.B.G.; resources, A.J. and R.B.G.; data curation, A.G., A.V.K., and R.S.H.; writing-original draft preparation, A.G., A.J., and R.B.G.; writingreview and editing, A.J., C.G.G., and R.B.G.; visualization, A.J., R.B.G., A.V.K., C.G.G., and R.S.H.; supervision, A.J. and R.B.G.; project administration, A.J., C.G.G., and R.B.G.; funding acquisition, A.J. and R.B.G. All authors have read and agreed to the published version of the manuscript.

Funding: This research received no external funding.

Acknowledgments: We are grateful to Stephen Wilcox for the technical support. This project was supported by the University of Melbourne as part of A.G.'s PhD research project. A.G. is a grateful recipient of the Research Training Scholarship from the Australian Government through the University of Melbourne.

Conflicts of Interest: The authors declare no conflict of interest.

\section{References}

1. Brown, C.G.D. Dynamics and impact of tick-borne diseases of cattle. Trop. Anim. Health Prod. 1997, 29, 1S-3S. [CrossRef] [PubMed]

2. Uilenberg, G. International collaborative research: Significance of tick-borne hemoparasitic diseases to world animal health Vet. Parasitol. 1995, 57, 19-41. [CrossRef]

3. De Castro, J.J. Sustainable tick and tickborne disease control in livestock improvement in developing countries. Vet. Parasitol. 1997, 71, 77-97. [CrossRef]

4. Bock, R.; Jackson, L.; De Vos, A.; Jorgensen, W. Babesiosis of cattle. Parasitology 2004, 129, S247-S269. [CrossRef] [PubMed]

5. Chauvin, A.; Moreau, E.; Bonnet, S.; Plantard, O.; Malandrin, L. Babesia and its hosts: Adaptation to long-lasting interactions as a way to achieve efficient transmission. Vet. Res. 2009, 40, 37. [CrossRef] [PubMed]

6. Zintl, A.; Mulcahy, G.; Skerrett, H.E.; Taylor, S.M.; Gray, J.S. Babesia divergens, a bovine blood parasite of veterinary and zoonotic importance. Clin. Microbiol. Rev. 2003, 16, 622-636. [CrossRef]

7. Földvári, G.; Široký, P.; Szekeres, S.; Majoros, G.; Sprong, H. Dermacentor reticulatus: A vector on the rise. Parasit. Vectors 2016, 9 , 1-29. [CrossRef]

8. Brown, W.C.; Palmer, G. Designing blood-stage vaccines against Babesia bovis and B. bigemina. Parasitol. Today 1999, 15, $275-281$. [CrossRef]

9. Suarez, C.E.; Noh, S. Emerging perspectives in the research of bovine babesiosis and anaplasmosis. Vet. Parasitol. 2011, 180, 109-125. [CrossRef] 
10. Bishop, R.P.; Musoke, A.; Morzaria, S.; Gardner, M.; Nene, V. Theileria: Intracellular protozoan parasites of wild and domestic ruminants transmitted by ixodid ticks. Parasitology 2004, 129, S271-S283. [CrossRef]

11. Gill, B.S.; Bhattacharyulu, Y.; Kaur, D. Symptoms and pathology of experimental bovine tropical theileriosis (Theileria annulata infection). Ann. Parasitol. Hum. Comparée 1977, 52, 597-608. [CrossRef] [PubMed]

12. Nietz, W. Theileriosis, gonderioses and cytauxzoonoses. Onderstepoort J. Vet. Res. 1956, 27, 275-430.

13. Martínez, J.A.A.; Rojas-Martínez, C.; Figueroa-Millán, J.V. Diagnostic tools for the identification of Babesia sp. in persistently infected cattle. Pathogens 2019, 8, 143. [CrossRef]

14. Wagner, G.; Cruz, D.; Holman, P.; Waghela, S.; Perrone, J.; Shompole, S.; Rurangirwa, F. Non-immunologic methods of diagnosis of babesiosis. Memórias Inst. Oswaldo Cruz 1992, 87, 193-199. [CrossRef] [PubMed]

15. Gubbels, J.M.; De Vos, A.P.; Van Der Weide, M.; Viseras, J.; Schouls, L.M.; De Vries, E.; Jongejan, F. Simultaneous detection of bovine Theileria and Babesia species by reverse line blot hybridization. J. Clin. Microbiol. 1999, 37, 1782-1789. [CrossRef] [PubMed]

16. Bursakov, S.A.; Kovalchuk, S.N. Co-infection with tick-borne disease agents in cattle in Russia. Ticks Tick Borne Dis. 2019, 10, 709-713. [CrossRef] [PubMed]

17. Perera, P.K.; Gasser, R.B.; Firestone, S.M.; Smith, L.; Roeber, F.; Jabbar, A. Semiquantitative multiplexed tandem PCR for detection and differentiation of four Theileria orientalis genotypes in cattle. J. Clin. Microbiol. 2015, 53, 79-87. [CrossRef]

18. Carr, I.M.; Robinson, J.I.; Dimitriou, R.; Markham, A.F.; Morgan, A.W.; Bonthron, D.T. Inferring relative proportions of DNA variants from sequencing electropherograms. Bioinformatics 2009, 25, 3244-3250. [CrossRef]

19. Gandhi, K.; Thera, M.A.; Coulibaly, I.; Traoré, K.; Guindo, A.B.; Doumbo, O.K.; Takala-Harrison, S.; Plowe, C.V. Next generation sequencing to detect variation in the Plasmodium falciparum circumsporozoite protein. Am. J. Trop. Med. Hyg. 2012, 86, 775-781. [CrossRef]

20. Glidden, C.K.; Koehler, A.V.; Hall, R.S.; Saeed, M.A.; Coppo, M.; Beechler, B.R.; Charleston, B.; Gasser, R.B.; Jolles, A.E.; Jabbar, A. Elucidating cryptic dynamics of Theileria communities in African buffalo using a high-throughput sequencing informatics approach. Ecol. Evol. 2019, 10, 70-80. [CrossRef]

21. Johnsen, J.M.; Nickerson, D.A.; Reiner, A.P. Massively parallel sequencing: The new frontier of hematologic genomics. Blood 2013, 122, 3268-3275. [CrossRef] [PubMed]

22. Bonnet, S.; Michelet, L.; Moutailler, S.; Cheval, J.; Hébert, C.; Vayssier-Taussat, M.; Eloit, M. Identification of parasitic communities within European ticks using next-generation sequencing. PLoS Negl. Trop. Dis. 2014, 8, e2753. [CrossRef] [PubMed]

23. Naveed, U.; Ali, Q.; Rashid, I.; Shabbir, M.Z.; Ijaz, M.; Abbas, M.; Evans, M.; Ashraf, K.; Morrison, I.; Morrison, L.; et al. Development of a deep amplicon sequencing method to determine the species composition of piroplasm haemoprotozoa. Ticks Tick Borne Dis. 2019, 10, 101276. [CrossRef]

24. Hinsu, A.T.; Thakkar, J.R.; Koringa, P.G.; Vrba, V.; Jakhesara, S.J.; Psifidi, A.; Guitian, J.; Tomley, F.; Rank, D.N.; Raman, M.; et al. Illumina Next Generation Sequencing for the Analysis of Eimeria Populations in Commercial Broilers and Indigenous Chickens. Front. Vet. Sci. 2018, 5, 176. [CrossRef]

25. Huggins, L.G.; Koehler, A.V.; Ng-Nguyen, D.; Wilcox, S.; Schunack, B.; Inpankaew, T.; Traub, R.J. A novel metabarcoding diagnostic tool to explore protozoan haemoparasite diversity in mammals: A proof-of-concept study using canines from the tropics. Sci. Rep. 2019, 9, 1-10. [CrossRef]

26. Koehler, A.V.; Jabbar, A.; Hall, R.S.; Gasser, R.B. A Targeted "Next-Generation" Sequencing-Informatic approach to define genetic diversity in Theileria orientalis populations within individual cattle: Proof-of-principle. Pathogens 2020, 9, 448. [CrossRef]

27. Šlapeta, J.; Saverimuttu, S.; Vogelnest, L.; Sangster, C.; Hulst, F.; Rose, K.; Thompson, P.; Whittington, R. Deep-sequencing to resolve complex diversity of apicomplexan parasites in platypuses and echidnas: Proof of principle for wildlife disease investigation. Infect. Genet. Evol. 2017, 55, 218-227. [CrossRef]

28. Jabbar, A.; Abbas, T.; Sandhu, Z.-U.-D.; Saddiqi, H.A.; Qamar, M.F.; Gasser, R.B. Tick-borne diseases of bovines in Pakistan: Major scope for future research and improved control. Parasit. Vectors 2015, 8, 1-13. [CrossRef]

29. Ali, Z.; Maqbool, A.; Muhammad, K.; Khan, M.; Younis, M. Prevalence of Theileria annulata infected hard ticks of cattle and buffalo in Punjab, Pakistan. Pak. Vet. J. 2013, 23, 20-26.

30. Ashraf, Q.U.; Khan, A.U.; Khattak, R.M.; Ali, M.; Shaikh, R.S.; Iqbal, F. A report on the high prevalence of Anaplasma sp. in buffaloes from two provinces in Pakistan. Ticks Tick Borne Dis. 2013, 4, 395-398. [CrossRef]

31. Atif, F.A. Prevalence of Anaplasma marginale, Babesia bigemina and Theileria annulata infections among cattle in Sargodha district, Pakistan. Afr. J. Agric. Res. 2012, 7, 3302-3307. [CrossRef]

32. Farooqi, S.H.; Ijaz, M.; Rashid, M.I.; Aqib, A.I.; Ahmad, Z.; Saleem, M.H.; Hussain, K.; Islam, S.; Naeem, H.; Khan, A. Molecular epidemiology of Babesia bovis in bovine of Khyber Pakhtunkhwa, Pakistan. Pak. Vet. J. 2017, 37, $275-280$.

33. Farooqi, S.H.; Ijaz, M.; Saleem, M.H.; Rashid, M.; Ahmad, S.S.; Islam, S.; Aqib, A.I.; Khan, A.; Hussain, K.; Khan, N.U. Prevalence and molecular diagnosis of Theileria annulata in bovine from three distinct zones of Khyber Pakhtunkhwa province, Pakistan. JAPS J. Anim. Plant Sci. 2017, 27, 1836-1841.

34. Hassan, M.A.; Liu, J.; Rashid, M.; Iqbal, N.; Guan, G.; Yin, H.; Luo, J.-X. Molecular survey of piroplasm species from selected areas of China and Pakistan. Parasit. Vectors 2018, 11, 1-7. [CrossRef] [PubMed]

35. Khan, M.K.; He, L.; Hussain, A.; Azam, S.; Zhang, W.-J.; Wang, L.-X.; Zhang, Q.-L.; Hu, M.; Zhou, Y.-Q.; Zhao, J. Molecular epidemiology of Theileria annulata and identification of $18 \mathrm{~S}$ rRNA gene and ITS regions sequences variants in apparently healthy buffaloes and cattle in Pakistan. Infect. Genet. Evol. 2013, 13, 124-132. [CrossRef] 
36. Qayyum, M.; Farooq, U.; Samad, H.; Chauhdry, H. Prevalence, clinicotherapeutic and prophylactic studies on theileriosis in district Sahiwal (Pakistan). J. Anim. Plant Sci. 2010, 20, 266-270.

37. Zeb, J.; Shams, S.; Din, I.U.; Ayaz, S.; Khan, A.; Nasreen, N.; Khan, H.; Khan, M.A.; Senbill, H. Molecular epidemiology and associated risk factors of Anaplasma marginale and Theileria annulata in cattle from North-western Pakistan. Vet. Parasitol. 2020, 279, 109044. [CrossRef]

38. Khan, A.G. Technical Report on the Characterization of the Agro Ecological Context in which FAnGR (Farm Animal Genetic Resource) Are Found; ILRI: Nairobi, Kenya, 2004.

39. Zia, U.E.; Mahmood, T.; Ali, M.R. Dairy Development in Pakistan; Food and Agriculture Organization of the United Nations: Rome, Italy, 2011.

40. R Core Team. R: A Language and Environment for Statistical Computing; R Foundation for Statistical Computing: Vienna, Austria, 2013; Available online: https:/ / www.R-project.org/ (accessed on 11 August 2018).

41. Bolyen, E.; Rideout, J.R.; Dillon, M.R.; Bokulich, N.A.; Abnet, C.C.; Al-Ghalith, G.A.; Alexander, H.; Alm, E.J.; Arumugam, M.; Asnicar, F.; et al. Reproducible, interactive, scalable and extensible microbiome data science using QIIME 2. Nat. Biotechnol. 2019, 37, 852-857. [CrossRef]

42. Martin, M. Cutadapt removes adapter sequences from high-throughput sequencing reads. EMBnet J. 2011, 17, 10-12. [CrossRef]

43. Callahan, B.J.; McMurdie, P.J.; Rosen, M.J.; Han, A.W.; Johnson, A.J.A.; Holmes, S.P. DADA2: High-resolution sample inference from Illumina amplicon data. Nat. Methods 2016, 13, 581-583. [CrossRef]

44. Callahan, B.J.; McMurdie, P.J.; Holmes, S.P. Exact sequence variants should replace operational taxonomic units in marker-gene data analysis. ISME J. 2017, 11, 2639-2643. [CrossRef] [PubMed]

45. Cooper, C.; Keatley, S.; Northover, A.; Gofton, A.W.; Brigg, F.; Lymbery, A.J.; Pallant, L.; Clode, P.L.; Thompson, R.A. Next generation sequencing reveals widespread trypanosome diversity and polyparasitism in marsupials from Western Australia. Int. J. Parasitol. Parasites Wildl. 2018, 7, 58-67. [CrossRef] [PubMed]

46. Pedregosa, F.; Varoquaux, G.; Gramfort, A.; Michel, V.; Thirion, B.; Grisel, O.; Blondel, M.; Prettenhofer, P.; Weiss, R.; Dubourg, V. Scikit-learn: Machine learning in Python. J. Mach. Learn. Res. 2011, 12, 2825-2830.

47. Katoh, K.; Asimenos, G.; Toh, H. Multiple alignment of DNA sequences with MAFFT. Methods Mol. Biol. 2009, 537, 39-64.

48. Price, M.N.; Dehal, P.S.; Arkin, A.P. FastTree 2-approximately maximum-likelihood trees for large alignments. PLoS ONE 2010, 5, e9490. [CrossRef]

49. Edgar, R.C. MUSCLE: Multiple sequence alignment with high accuracy and high throughput. Nucleic Acids Res. 2004, 32, 1792-1797. [CrossRef]

50. Kumar, S.; Stecher, G.; Tamura, K. MEGA7: Molecular evolutionary genetics analysis version 7.0 for bigger datasets. Mol. Biol. Evol. 2016, 33, 1870-1874. [CrossRef]

51. Hall, T.A. BioEdit: A user-friendly biological sequence alignment editor and analysis program for Windows 95/98/NT. In Nucleic Acids Symposium Series; Information Retrieval Ltd.: London, UK, 1999; Volume 41, pp. 95-98.

52. Darriba, D.; Taboada, G.L.; Doallo, R.; Posada, D. jModelTest 2: More models, new heuristics and parallel computing. Nat. Methods 2012, 9, 772. [CrossRef]

53. Tamura, K.; Nei, M. Estimation of the number of nucleotide substitutions in the control region of mitochondrial DNA in humans and chimpanzees. Mol. Biol. Evol. 1993, 10, 512-526. [CrossRef]

54. Felsenstein, J. Confidence limits on phylogenies: An approach using the bootstrap. Evolution 1985, 39, 783. [CrossRef]

55. Wickham, H. Ggplot2. Wiley Interdiscip. Rev. Comput. Stat. 2011, 3, 180-185. [CrossRef]

56. McMurdie, P.J.; Holmes, S. Phyloseq: An R Package for reproducible interactive analysis and graphics of microbiome census data. PLoS ONE 2013, 8, e61217. [CrossRef] [PubMed]

57. Conway, J.R.; Lex, A.; Gehlenborg, N. UpSetR: An R package for the visualization of intersecting sets and their properties. Bioinformatics 2017, 33, 2938-2940. [CrossRef] [PubMed]

58. Government of Pakistan. Pakistan Economic Survey 2019-2020; Ministry of Finance: Islamabad, Pakistan, 2020 ; pp. 17-41.

59. Ghafar, A.; Gasser, R.B.; Rashid, I.; Ghafoor, A.; Jabbar, A. Exploring the prevalence and diversity of bovine ticks in five agro-ecological zones of Pakistan using phenetic and genetic tools. Ticks Tick Borne Dis. 2020, 11, 101472. [CrossRef] [PubMed]

60. Rehman, A.; Nijhof, A.M.; Sauter-Louis, C.; Schauer, B.; Staubach, C.; Conraths, F.J. Distribution of ticks infesting ruminants and risk factors associated with high tick prevalence in livestock farms in the semi-arid and arid agro-ecological zones of Pakistan. Parasit. Vectors 2017, 10, 1-15. [CrossRef]

61. Pipano, E.; Shkap, V. Vaccination against tropical theileriosis. Ann. N. Y. Acad. Sci. 2000, 916, 484-500. [CrossRef]

62. Sajid, M.S.; Iqbal, Z.; Khan, M.N.; Muhammad, G.; Khan, M.K. Prevalence and associated risk factors for bovine tick infestation in two districts of lower Punjab, Pakistan. Prev. Vet. Med. 2009, 92, 386-391. [CrossRef]

63. Bock, R.E.; De Vos, A.J.; Kingston, T.G.; McLellan, D.J. Effect of breed of cattle on innate resistance to infection with Babesia bovis, B. bigemina and Anaplasma marginale. Aust. Vet. J. 1997, 75, 337-340. [CrossRef]

64. Glass, E.J.; Preston, P.M.; Springbett, A.; Craigmile, S.; Kirvar, E.; Wilkie, G.; Brown, C.D. Bos taurus and Bos indicus (Sahiwal) calves respond differently to infection with Theileria annulata and produce markedly different levels of acute phase proteins. Int. J. Parasitol. 2005, 35, 337-347. [CrossRef] 
65. Larcombe, S.; Kolte, S.; Ponnudurai, G.; Kurkure, N.; Magar, S.; Velusamy, R.; Rani, N.; Rubinibala, B.; Rekha, B.; Alagesan, A.; et al. The impact of tick-borne pathogen infection in Indian bovines is determined by host type but not the genotype of Theileria annulata. Infect. Genet. Evol. 2019, 75, 103972. [CrossRef]

66. Calleja-Bueno, L.; Sainz, A.; García-Sancho, M.; Rodríguez-Franco, F.; González-Martín, J.V.; Villaescusa, A. Molecular, epidemiological, haematological and biochemical evaluation in asymptomatic Theileria annulata infected cattle from an endemic region in Spain. Ticks Tick Borne Dis. 2017, 8, 936-941. [CrossRef] [PubMed]

67. Aktas, M.; Altay, K.; Dumanli, N. A molecular survey of bovine Theileria parasites among apparently healthy cattle and with a note on the distribution of ticks in eastern Turkey. Vet. Parasitol. 2006, 138, 179-185. [CrossRef] [PubMed]

68. Lefterova, M.I.; Suarez, C.J.; Banaei, N.; Pinsky, B.A. Next-generation sequencing for infectious disease diagnosis and management: A report of the Association for Molecular Pathology. J. Mol. Diagn. 2015, 17, 623-634. [CrossRef] [PubMed]

69. Mao, R.; Xiao, S.; Lin, R.; Wang, Y.; Wang, T. Technical validation of a high-sensitivity target capture NGS assay using unique molecular identifier approach. J. Clin. Oncol. 2020, 38, e13657. [CrossRef]

70. Gebrekidan, H.; Perera, P.K.; Ghafar, A.; Abbas, T.; Gasser, R.B.; Jabbar, A. An appraisal of oriental theileriosis and the Theileria orientalis complex, with an emphasis on diagnosis and genetic characterisation. Parasitol. Res. 2019, 119, 11-22. [CrossRef] [PubMed]

71. Aparna, M.; Ravindran, R.; Vimalkumar, M.; Lakshmanan, B.; Rameshkumar, P.; Kumar, K.A.; Promod, K.; Ajithkumar, S.; Ravishankar, C.; Devada, K.; et al. Molecular characterization of Theileria orientalis causing fatal infection in crossbred adult bovines of South India. Parasitol. Int. 2011, 60, 524-529. [CrossRef]

72. Sivakumar, T.; Kothalawala, H.; Abeyratne, S.A.E.; Vimalakumar, S.C.; Meewewa, A.S.; Hadirampela, D.T.; Puvirajan, T.; Sukumar, S.; Kuleswarakumar, K.; Chandrasiri, A.D.N.; et al. A PCR-based survey of selected Babesia and Theileria parasites in cattle in Sri Lanka. Vet. Parasitol. 2012, 190, 263-267. [CrossRef]

73. Liu, A.H.; Guan, G.Q.; Liu, J.L.; Liu, Z.J.; Leblanc, N.; Li, Y.Q.; Gao, J.L.; Ma, M.L.; Niu, Q.L.; Ren, Q.Y.; et al. Polymorphism analysis of Chinese Theileria sergenti using allele-specific polymerase chain reaction of the major piroplasm surface protein gene. J. Parasitol. 2011, 97, 116-121. [CrossRef]

74. Gebrekidan, H.; Abbas, T.; Wajid, M.; Ali, A.; Gasser, R.B.; Jabbar, A. Molecular characterisation of Theileria orientalis in imported and native bovines from Pakistan. Infect. Genet. Evol. 2017, 47, 19-25. [CrossRef]

75. Gebrekidan, H.; Gasser, R.B.; Perera, P.K.; McGrath, S.; McGrath, S.; Stevenson, M.A.; Jabbar, A. Investigating the first outbreak of oriental theileriosis in cattle in South Australia using multiplexed tandem PCR (MT-PCR). Ticks Tick Borne Dis. 2015, 6, 574-578. [CrossRef]

76. Perera, P.K.; Gasser, R.B.; Anderson, G.A.; Jeffers, M.; Bell, C.M.; Jabbar, A. Epidemiological survey following oriental theileriosis outbreaks in Victoria, Australia, on selected cattle farms. Vet. Parasitol. 2013, 197, 509-521. [CrossRef] [PubMed]

77. Benitez, D.; Mesplet, M.; Echaide, I.; De Echaide, S.T.; Schnittger, L.; Florin-Christensen, M. Mitigated clinical disease in water buffaloes experimentally infected with Babesia bovis. Ticks Tick Borne Dis. 2018, 9, 1358-1363. [CrossRef] [PubMed]

78. Jaimes-Dueñez, J.; Triana-Chavez, O.; Holguín-Rocha, A.; Tobón-Castaño, A.; Mejia-Jaramillo, A.M. Molecular surveillance and phylogenetic traits of Babesia bigemina and Babesia bovis in cattle (Bos taurus) and water buffaloes (Bubalus bubalis) from Colombia. Parasit. Vectors 2018, 11, 510. [CrossRef] [PubMed]

79. Bhoora, R.; Franssen, L.; Oosthuizen, M.C.; Guthrie, A.J.; Zweygarth, E.; Penzhorn, B.L.; Jongejan, F.; Collins, N.E. Sequence heterogeneity in the $18 \mathrm{~S}$ rRNA gene within Theileria equi and Babesia caballi from horses in South Africa. Vet. Parasitol. 2009, 159, 112-120. [CrossRef] [PubMed]

80. Chae, J.-S.; Allsopp, B.A.; Waghela, S.D.; Park, J.-H.; Kakuda, T.; Sugimoto, C.; Allsopp, M.T.E.P.; Wagner, G.G.; Holman, P.J. A study of the systematics of Theileria spp. based upon small-subunit ribosomal RNA gene sequences. Parasitol. Res. 1999, 85, 877-883. [CrossRef] [PubMed]

81. Gubbels, M.-J.; Hong, Y.; Van Der Weide, M.; Qi, B.; Nijman, I.J.; Guangyuan, L.; Jongejan, F. Molecular characterisation of the Theileria buffeli/orientalis group. Int. J. Parasitol. 2000, 30, 943-952. [CrossRef]

82. Mans, B.J.; Pienaar, R.; Latif, A.A.; Potgieter, F.T. Diversity in the 18S SSU rRNA V4 hyper-variable region of Theileria spp. in Cape buffalo (Syncerus caffer) and cattle from southern Africa. Parasitology 2011, 138, 766-779. [CrossRef]

83. Zakian, A.; Nouri, M.; Barati, F.; Kahroba, H.; Jolodar, A.; Rashidi, F. Vertical transmission of Theileria lestoquardi in sheep. Vet. Parasitol. 2014, 203, 322-325. [CrossRef]

84. Jalali, S.M.; Jolodar, A.; Rasooli, A.; Darabifard, A. Detection of Theileria lestoquardi cross infection in cattle with clinical theileriosis in Iran. Acta Parasitol. 2016, 61, 756-761. [CrossRef]

85. Taha, K.; Salih, D.; Ali, A.; Omer, R.; El Hussein, A. Naturally occurring infections of cattle with Theileria lestoquardi and sheep with Theileria annulata in the Sudan. Vet. Parasitol. 2013, 191, 143-145. [CrossRef]

86. Ahmed, J.S.; Schnittger, L.; Yin, H.; Gubbels, M.J.; Beyer, D.; Jongejan, F.; Niemann, S. Phylogeny of sheep and goat Theileria and Babesia parasites. Parasitol. Res. 2003, 91, 398-406. [CrossRef] [PubMed]

87. Katzer, F. Phylogenetic analysis of Theileria and Babesia equi in relation to the establishment of parasite populations within novel host species and the development of diagnostic tests. Mol. Biochem. Parasitol. 1998, 95, 33-44. [CrossRef]

88. Leemans, I.; Hooshmand-Rad, P.; Uggla, A. The indirect fluorescent antibody test based on schizont antigen for study of the sheep parasite Theileria lestoquardi. Vet. Parasitol. 1997, 69, 9-18. [CrossRef] 
89. Gray, J.S.; De Vos, A.J. Studies on a bovine Babesia transmitted by Hyalomma marginatum rufipes Koch, 1844. Onderstepoort J. Vet. Res. 1981, 48, 215-223. [PubMed]

90. De Caro, N.; LaRocca, V.; Parisi, A.; Losurdo, M.; Lia, R.P.; Greco, M.F.; Miccolis, A.; Ventrella, G.; Otranto, D.; Buonavoglia, C. Clinical bovine piroplasmosis caused by Babesia occultans in Italy. J. Clin. Microbiol. 2013, 51, 2432-2434. [CrossRef] [PubMed]

91. Ghafar, A.; Cabezas-Cruz, A.; Galon, C.; Obregon, D.; Gasser, R.B.; Moutailler, S.; Jabbar, A. Bovine ticks harbour a diverse array of microorganisms in Pakistan. Parasit. Vectors 2020, 13, 1-15. [CrossRef] [PubMed] 